\title{
Neolithisation at the site Brandwijk-Kerkhof, the Netherlands: natural vegetation, human impact and plant food subsistence
}

\author{
Welmoed A. Out
}

Received: 24 April 2006/Accepted: 28 October 2006/Published online: 19 June 2007

(C) Springer-Verlag 2007

\begin{abstract}
Brandwijk-Kerkhof (ca. 4600 to 3630 cal в.c.) is a Neolithic site, located on a river dune in the Dutch Rhine/Maas river area. The natural vegetation and human impact upon it have been investigated by analysis of pollen and macroremains from four cores that are located at increasing distances up to $20 \mathrm{~m}$ from the site. The relationship between the strength of human impact on the vegetation and the distance of the cores from the river dune has been investigated as well. The results show that the natural vegetation on top of the river dune consisted of deciduous woodland, while in the surrounding wetlands alder carr and eutrophic marsh vegetation dominated. Human impact of limited strength resulted in more open and disturbed vegetation. There is no correlation between the strength of the evidence of human impact in the pollen diagrams and the distance of the cores from the river dune. The evidence for presence of crop plants from the cores is compared with evidence from the excavation. The first presence of crop plants from ca. 4200 в.c. onwards corresponds with data from other Dutch wetland sites. Large-scale local crop cultivation cannot however be demonstrated.
\end{abstract}

Keywords Pollen analysis - Botanical macroremains . Human impact · Neolithisation · Crop cultivation . Swifterbant culture

Electronic supplementary material The online version of this article (doi:10.1007/s00334-007-0108-8) contains supplementary material, which is available to authorized users.

W. A. Out $(\bowtie)$

Faculty of Archaeology, Leiden University, PO Box 9515, 2300 RA Leiden, The Netherlands

e-mail: w.a.out@arch.leidenuniv.nl

\section{Introduction}

The cultural setting

The Neolithic started in the Netherlands with arrival of the fully Neolithic Linearbandkeramik culture in the southern loess region of the Netherlands at ca. 5300 cal в.C., resulting in a long-lasting open frontier between Mesolithic and Neolithic societies. From ca. 4750 B.c. onwards, the Neolithic Rössen culture was present in the loess region, followed by the Michelsberg culture at ca. 4300 в.c. In the remaining parts of the Netherlands, the Neolithisation process was gradual, characterised by introduction of pottery at ca. 5000 в.c., introduction of domestic animals at ca. 4700 в.с. and introduction of crop plants at least by ca. 4300-4000 в.С., although earlier introduction of crop plants (after 4500 в.с.) cannot be excluded (Brinkkemper et al. 1999; Louwe Kooijmans 2003; Raemaekers 1999). It is not, however, known how far this reconstruction of the gradual Neolithisation process, based on wetland sites where preservation of organic remains is excellent, is representative of southern and eastern sandy regions in the Netherlands (Louwe Kooijmans 1993).

Brandwijk-Kerkhof (Alblasserwaard, Zuid-Holland), named Brandwijk here, is a site of the Neolithic Swifterbant culture. This culture covered large parts of the Netherlands as well as wetland regions of northwestern Belgium and northwestern Germany in the period 5000-3400 в.с. The site was occupied periodically from ca. 4600 to $3630 \mathrm{cal}$ B.C. Other sites in the Alblasserwaard that are highly comparable with Brandwijk are Hardinxveld-Giessendam Polderweg (5500-5000 в.c.), Hardinxveld-Giessendam De Bruin (5500-4500 в.с.) and the Hazendonk (4000-2500 в.с.) (Louwe Kooijmans 1974, 2003). All sites are interpreted as places where people came primarily for hunting, 
fishing, fowling and gathering. The first two stages of the gradual Neolithisation process are present at HardinxveldGiessendam Polderweg and De Bruin and are characterised by introduction of pottery first and domestic animals later, while cultivated plants are absent (Louwe Kooijmans 2003). In contrast, the Hazendonk is a fully Neolithic site. Interestingly, the Brandwijk site fills part of the gap in time and data between the Hardinxveld-Giessendam sites and the Hazendonk. In order to study the developed stage of the Neolithic at Brandwijk, pollen and macrofossil data from the site are presented here. The questions considered here are:

1. What did the natural vegetation of the river dune and its direct surroundings look like?

2. How can we characterise human impact on the vegetation?

3. Is there a relationship between the strength of human impact on the vegetation and the distance from the river dune?

4. Which crop plants were present and when were crop plants first introduced at the site?

5. Was crop cultivation practised at the site?

The hypothesis concerning the third question is that the indications of human impact on the natural vegetation diminish when the distance between the sample point and the river dune increases. This hypothesis is based on the faint signs of human impact in pollen diagrams from the Hardinxveld-Giessendam sites (Bakels and Van Beurden 2001; Bakels et al. 2001).

The site

The site at Brandwijk was partially excavated in 1991 by a team from Leiden University under the direction of Van Gijn and Verbruggen in a research project on Neolithic occupation on late-glacial river dunes. At Brandwijk, Swifterbant pottery was found in all layers. The flint assemblage indicated contacts with southern regions, and fragments of flint axes at the base and top of layer 50 indicate incorporation of the Michelsberg material culture (Raemaekers 1999). There were no structures present except for a series of pointed posts (dating to layer 50 or later). The bone assemblage was dominated by beaver, otter, deer and wild boar. Bones of domestic animals (dog, goat/sheep, cattle and pig) were present from initial occupation onwards but only formed a minority of the assemblage. Preliminary results indicate that the site was used as a temporary hunting/fishing camp. The similarity of the mammal and fish faunas through the layers suggests consistency of site function through time (Van Gijn and Verbruggen 1992; Raemaekers 1999).

The excavation trench $(3 \times 15 \mathrm{~m})$ was situated on the southern slope of the river dune. Several find layers were
Table 1 Find layers at Brandwijk-Kerkhof

\begin{tabular}{lll}
\hline Layer & Age (cal в.с.) & Surface \\
\hline 70 & $3700-3630$ & \\
60 & $3940-3820$ & $1,600 \mathrm{~m}^{2}$ \\
50 top & $4030-3940$ & $1,500 \mathrm{~m}^{2}$ \\
50 base & $4220-4100$ & $1,500 \mathrm{~m}^{2}$ \\
45 & $4470-4370$ & \\
30 & $4610-4550$ & $200 \mathrm{~m}^{2}$ \\
\hline
\end{tabular}

distinguished in the excavation trench (see Table 1). Layers 30 and 45 are interpreted as minor occupation periods while layers 50 and 60 represent more intensive ones. Layer 70 contained only a single sherd and is not considered as a true find layer. The distinction between layer 50 base and 50 top was only made after excavation. Layer 60, which is later than layer 50, merged with layer 50 on the slope of the river dune (Raemaekers 1999; M. Verbruggen, personal communication).

Geology and landscape

Brandwijk is a small river dune in the sedimentation area of the lower courses of the Rhine and Maas, the Dutch Rhine/ Maas river area (Fig. 1). It is an outcrop of Pleistocene sand deposited during the late Weichselian (Verbraeck 1974). The top of the dune reaches ca. -0.5 m NAP (Dutch Ordnance Datum) and the diameter of the dune during occupation was ca. $75 \mathrm{~m}$. The sediment in the direct surroundings of the river dune mainly consists of peat. A clay layer in the peat, at ca. $15 \mathrm{~m}$ in a southern direction from the river dune, indicates the presence of open water during formation of layer 30. Clay was deposited at the northwestern side of the site during formation of layers 50 and 60 (M. Verbruggen, personal communication). A larger river dune named Brandwijk-Donk is present at ca. $250 \mathrm{~m}$ in a northwestern direction. At the time of occupation, the landscape in the central river area was dominated by river channels, lakes and alder carr vegetation. Sedimentation took place under relatively calm conditions. The rise of the Mean Sea Level resulted in a gradual rise of the ground water level in the region, leading to a gradual decrease of the surface of the river dune and drowning of the local dry land vegetation (Van der Woude 1983).

\section{Materials and methods}

\section{Samples}

The research strategy was to concentrate on a single find layer in order to allow reconstruction of the vegetation 


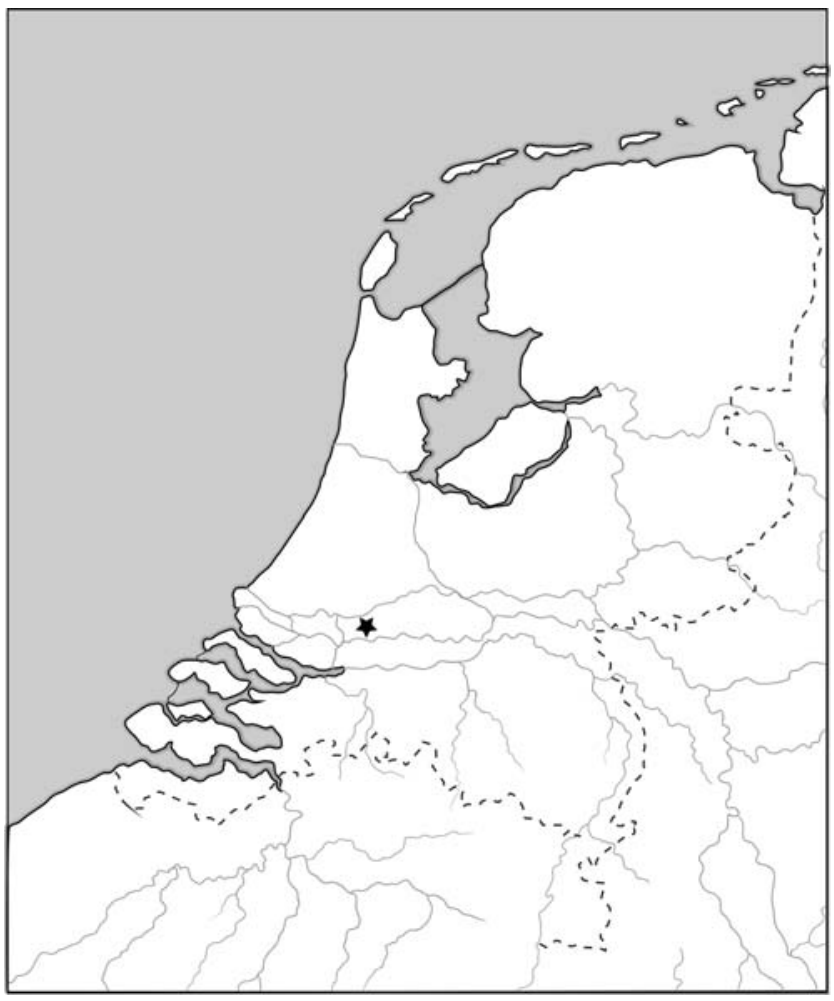

Fig. 1 Location of the site of Brandwijk-Kerkhof, the Netherlands

before, during and after a single occupation period. A transect of four cores was made at 1, 5, 10 and $20 \mathrm{~m}$ from the river dune in order to perform analyses of pollen and macroremains (Fig. 2). The top of the investigated find layer was in contact with the sand of the river dune. Figure 3 shows the positions and the lengths of the cores, the presence of charcoal and bone remains (including fish remains) and ${ }^{14} \mathrm{C}$ dates. The sediment of all cores consisted of dark brown peat.

The size of samples used for pollen analysis was $1 \mathrm{~cm}^{3}$. The sample interval was generally $10 \mathrm{~cm}$. The samples were prepared according to the standard methods (Fægri and Iversen 1989) and to each sample a Lycopodium tablet was added. The samples were analysed with a microscope at magnifications of $400 \times$ and $640 \times$ by W.J. Kuijper, L. van Beurden, A. Reinink and D. Paetzold. Identification was based on literature (Fægri and Iversen 1989; Moore et al. 1991) and the reference collection of the institute. Identification of Cerealia-type pollen was based on the diameter of the grain and the ratio of the diameters of the annulus and the pore. Cores $\mathrm{A}$ and $\mathrm{C}$ were partly analysed: only samples from that part of the core containing charcoal and/ or bone remains were selected. Data were converted to percentage diagrams with the software programs Tilia v2.0.b.4 and TGView v2.0.2 (Grimm 1991-1993, 2004). The pollen sum (300 pollen grains if possible) includes dry land trees, shrubs, herbs and pterydophytes such as ferns

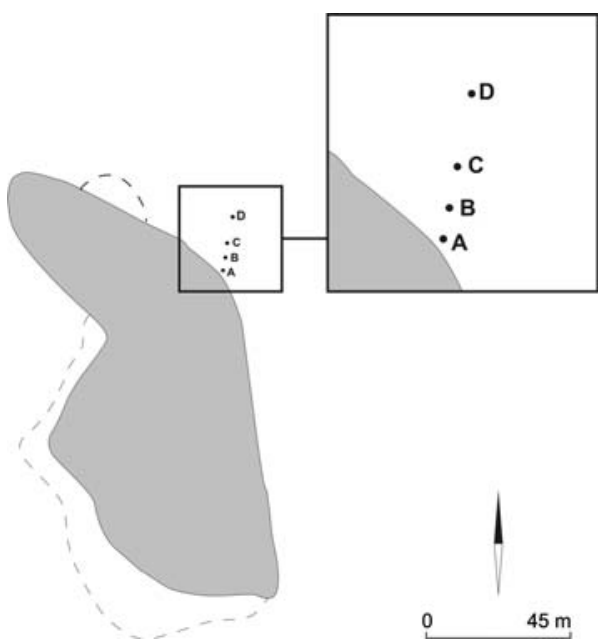

Fig. 2 Location map: location of the four investigated cores plotted on the site map showing the surface of the river dune at ca. 4200 3950 в.c. (grey surface) and the distribution of find layer 50 (dotted line) Prospective investigation indicated that other find layers were restricted to the southern side of the river dune. With kind permission of M. Verbruggen and D.C.M. Raemaekers

and mosses, enabling representative analysis of changes in the dry land vegetation. Exaggeration is fivefold, if applied. The classification of plants into ecological groups is based on Schamineé et al. (1995-1999).

The four cores used for pollen and spore analysis were divided into samples of $5 \mathrm{~cm}$ thickness that were all used for macroremains analysis. The size of the macroremains samples was ca. $25 \mathrm{~cm}^{3}$. A fragment of wood prevented regular sampling of macroremains in core $\mathrm{D}$ at $-6.27 \mathrm{~m}$. W.J. Kuijper and L. van Beurden analysed the macroremains with a binocular microscope at a magnification of 6 to $40 \times$, and identifications were based on the literature and the reference collection of the institute. The results were calculated and drawn up with Tilia v2.0.b.4 and TGView v2.0.2. The diagrams show absolute numbers of seeds. Straight lines indicate borders of biostratigraphical zones, while dotted lines indicate the part of the core that was subjected to pollen analysis. Names of plant species are given according to Van der Meijden (1996). The excavation included analysis of botanical macroremains as well, but only highly relevant results will be preliminarily presented here. The samples of macroremains from layer 50 of the excavation cannot be allocated to the base or top of layer 50. Galeopsis-type represents G. bifida/speciosaltetrahit; Ranunculus repens-type represents $R$. acris/lingual repens but it probably concerns $R$. repens here.

Dates

Peat samples from cores B and D were selected and sent to the Groningen Centre for Isotope Research for ${ }^{14} \mathrm{C}$ dating. 
Fig. 3 Core transect: the depth of the four cores in metres below NAP (Dutch Ordnance Datum), the location of the cores in metres distance to the river dune, and ${ }^{14} \mathrm{C}$ dates (B.P.). The sediment of all cores consisted of peat

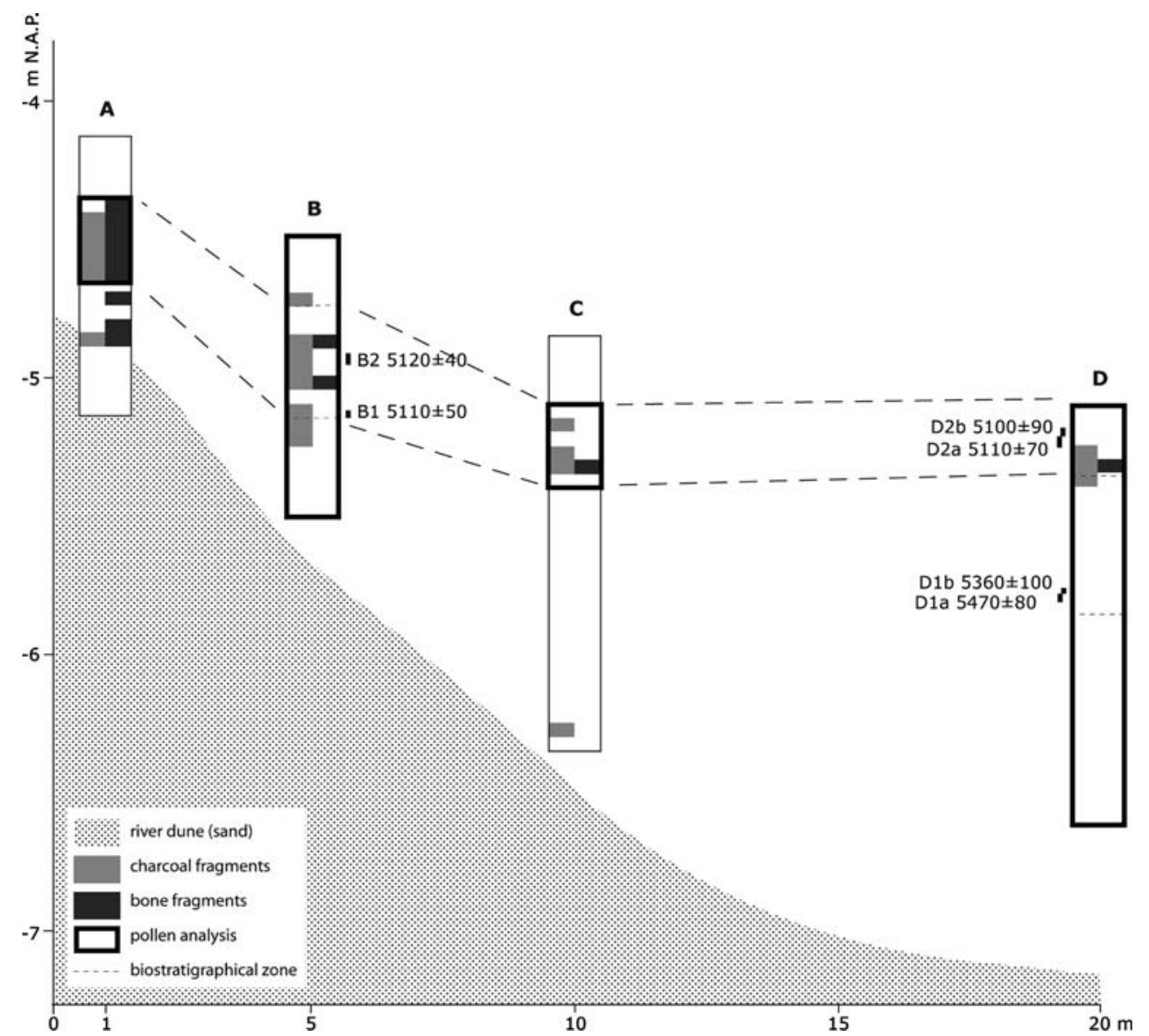

The dates are calibrated with Oxcal v3.10 (Bronk Ramsey 2005). Table 2 shows the results of the ${ }^{14} \mathrm{C}$ dating and the correspondence between the dates and the find layers. Dates D2b, D2a, B1 and B2 all represent the same find layer that is present in all the cores, which is contemporary with the top of layer 50 and/or with layer 60 which were observed in the excavation trench. The find layer in the cores is certainly contemporary with layer 60 when considering the contact point of the top of layer 60 in the excavation trench $(-4.00 \mathrm{~m})$ and the gradient of the find layer in the cores (M. Verbruggen, personal communication). The layer may furthermore represent a combination of layers due to the merging of separate layers and therefore possibly also represents older layers contemporary with the top of layer 50 .

\section{Results}

Pollen analysis

The ${ }^{14} \mathrm{C}$ dates and stratigraphy indicate that the pollen diagrams of cores $\mathrm{A}$ and $\mathrm{C}$, the middle part of core $\mathrm{B}$ and the upper part of core D correspond with each other
(Fig. 3). The lower part of core B corresponds with the middle part of core $\mathrm{D}$. The results start with presentation of the pollen analysis of cores D and B that were extensively investigated by pollen analysis, followed by the pollen analysis results of cores $\mathrm{C}$ and $\mathrm{A}$, and afterwards the presentation of the macroremains analysis of all cores. The diagram of core D is divided into three zones (Fig. 4 and Appendix 1). Zone D-I is characterised by high percentages of Tilia compared with following zones and fluctuating values of Quercus. The concentration diagram (not presented here) and the macroremains show that Quercus was an important element of the local vegetation mainly at the beginning and the end of the zone. The variety of dry land shrubs demonstrates presence of open patches and woodland edge vegetation. In the wetland vegetation dense stands of Alnus glutinosa were present, probably with undergrowth of Cyperaceae and ferns (represented by monoletae psilatae spores). Alder grows on eutrophic and permanent wet substrates, and cannot stand strong water flow in summer (Weeda et al. 1985). Herbs at the beginning and at the end of the zone indicate that the vegetation was somewhat open (for example pollen of Mentha-type and the climber Humulus lupulus). 
Table 2 Radiocarbon dates of the cores of Brandwijk

\begin{tabular}{|c|c|c|c|c|c|}
\hline Code & Depth (m. - NAP) & Lab. code & Age B.P. & Age cal в.с. $(2 \sigma)$ & Corresponds with layer \\
\hline B2 & $4.95-4.92$ & GrN-24048 & $5120 \pm 40$ & $3990(95.4 \%) 3790$ & 50 top/60 \\
\hline B1 & $5.15-5.12$ & GrN-24047 & $5110 \pm 50$ & $\begin{array}{l}4040(1.4 \%) 4020 \\
4000(94.0 \%) 3780\end{array}$ & 50 top/60 \\
\hline $\mathrm{D} 2 \mathrm{~b}$ & $5.22-5.19$ & GrN-24050 & $5100 \pm 90$ & $4250(95.4 \%) 3650$ & 50 top/60 (50 base) \\
\hline $\mathrm{D} 2 \mathrm{a}$ & $5.26-5.23$ & GrN-24109 & $5110 \pm 70$ & $4050(95.4 \%) 3710$ & 50 top/60 \\
\hline D1b & $5.78-5.76$ & GrN-24049 & $5360 \pm 100$ & $4370(95.4 \%) 3960$ & 50 base \\
\hline D1a & $5.81-5.79$ & GrN-24108 & $5470 \pm 80$ & $\begin{array}{l}4470(81.4 \%) 4220 \\
4210(6.9 \%) 4150 \\
4140(7.1 \%) 4050\end{array}$ & 45 (50 base) \\
\hline
\end{tabular}

In the column of correspondence of dates with layers, the brackets indicate the less likely options of correspondence

Zone D-II is characterised by a temporary decrease in the percentage of Quercus in the lower part of the zone, followed by an increase of shrubs such as Corylus and Viburnum opulus. The peak of Pinus probably reflects regional pollen deposited during a period characterised by very open vegetation. The concentration diagram shows a similar decrease of Quercus, peak of Pinus and increase of shrubs as well. The wetland vegetation in this zone is characterised by fluctuations of Alnus and an increase of the marsh/riparian vegetation. The values of Cyperaceae, monoletae psilatae spores, Apiaceae, Filipendula, Galiumtype, Urtica dioica-type, Sparganium erectum-type, Valeriana and $H$. lupulus increase, which indicates open and eutrophic conditions. Altogether these changes indicate that both the dry land and the wetland vegetation became more open. At $-5.51 \mathrm{~m}$, the landscape furthermore gradually became wetter. This is indicated by the presence of Sagittaria sagittifolia-type, Nymphaea alba-type, Potamogeton, Salvinia natans and Pediastrum. These indicate the presence of calm open water and this partly explains the open environment. S. natans is an indicator species of the Atlantic and has been found regularly in deposits from the Rhine delta (Zandstra 1966).

Zone D-III is characterised by a strong increase of dry land herbs, anthropogenic indicators and some wetland herbs, followed by an increase of dry land shrubs (discussed below). Quercus is locally present at $-5.26 \mathrm{~m}$. The low values and absence of macroremains of Tilia as well as the increased values of Fraxinus and Betula may be related to a rise of the water table in the extra-local area, since Tilia grows on relatively dry soils while both Betula and Fraxinus tolerate wetter soils. Alnus shows fluctuating but generally decreased values and water plants are still well represented.

The diagram of core $\mathrm{B}$ is divided into three zones (Fig. 5 and Appendix 1). Zone B-I is characterised by a peak of Tilia and low percentages of dry land herbs. Tilia, Quercus, Corylus and Fraxinus are dominant in the river dune vegetation in this zone. The high value of Tilia is confirmed by the concentration diagram and indicates its local presence. The concentration diagram indicates that Quercus did not decrease (in contrast to the percentage diagram). Shrubs appear at the end of the zone. In the wetland vegetation, alder soon decreases after the first part of the zone while Cyperaceae increase. Other important elements are ferns and Poaceae. Continuous presence of pollen of Potamogeton indicates the presence of open water.

Zone B-II is characterised by an increase of dry land herbs and shrubs and low values of Tilia, indicating absence of lime in the local vegetation. Fraxinus, Betula and Rhamnus cathartica show a slight increase and Prunus is present, all indicating presence of open patches in the vegetation. The increase of Pinus is probably related to an increased influx of regional pollen since the dry land herbs and the wetland taxa indicate relatively open vegetation. Anthropogenic indicators are present (discussed below). In the wetland vegetation, Alnus decreases, after which Poaceae, Cyperaceae, Asteraceae tubuliflorae and monoletae psilatae spores show high values. The peak of Asteraceae tubuliflorae indicates local presence of Asteraceae and corresponds with core C. The presence of Nuphar lutea-type, Myriophyllum verticillatum, Spirogyra and Zygnemataceae indicate a very wet phase (corresponding with core D).

Zone B-III is characterised by an increase of Tilia and stable though relatively high values of dry land herbs. Zone B-III probably represents a time period later than the upper part of core D and the analysed parts of cores A and C. Unfortunately, the pollen sums of the spectra are very low, limiting the possibility of making detailed conclusions, for example about the low values of Ulmus and Fraxinus. The concentration diagram indicates that the increase of Tilia is a true increase and not an artificial result of the decrease of Quercus. Poaceae (probably representing Phragmites), Alnus, Filipendula and Asteraceae tubuliflorae were dominant in the wetland vegetation although the macroremains diagram indicates a minor importance of Alnus. 

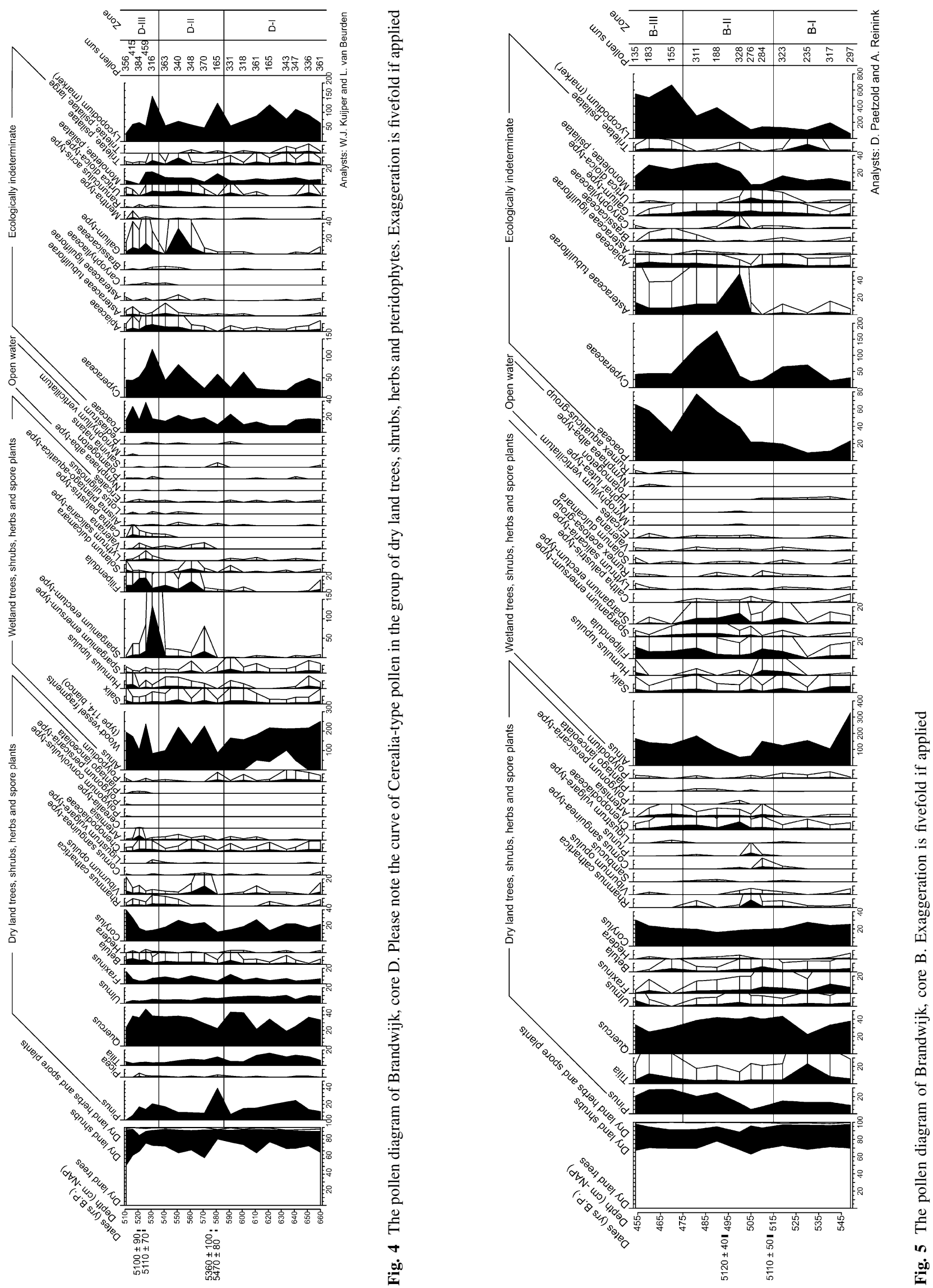

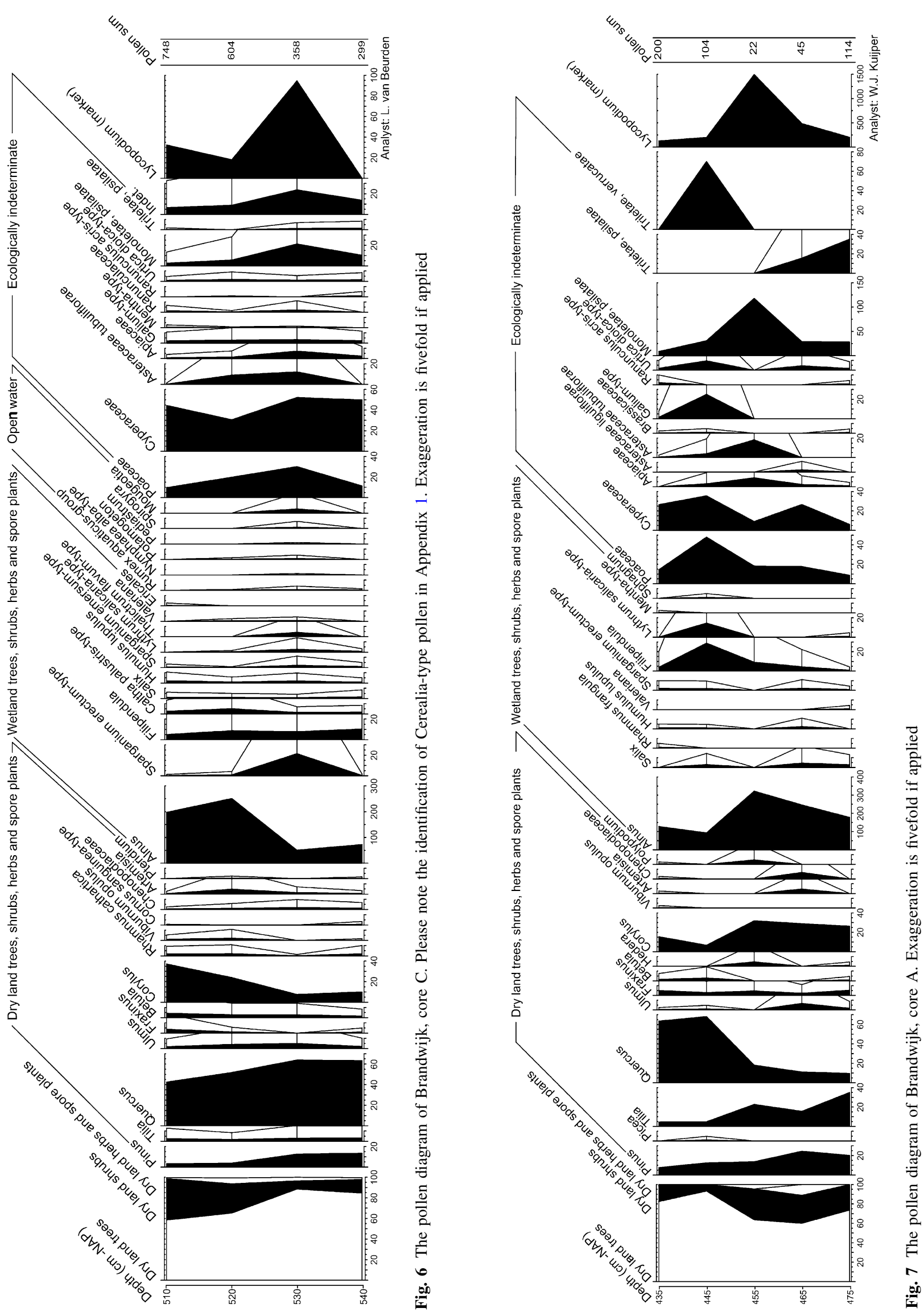
The pollen diagrams of core $\mathrm{C}$ and core $\mathrm{A}$ give relatively little information because of the limited number of analysed spectra and the poor preservation of the pollen grains. Core C (Fig. 6 and Appendix 1) shows that Quercus and Corylus were important taxa. A decrease of dry land tree pollen is followed by an increase of dry land shrubs and herbs. The lower part of the diagram is characterised by open wetland vegetation, indicated by high values of Cyperaceae, Poaceae, $S$. erectum-type, fern spores and Asteraceae tubuliflorae. This coincides with presence of indicators of open water. Alnus increases in the upper part of the diagram while the wetland herbs decrease, suggesting recovery of the vegetation.

In the lower part of the diagram from core A (Fig. 7), Tilia and Corylus are important taxa, and several herbs show peak values. Afterwards, the importance of herbs decreases and Quercus becomes dominant. The pollen sums of this diagram are, however, very low, limiting the accuracy of the data. The upper part of the macroremains diagram of core A contains a seed of Tilia which indicates that lime remained present on the top of the dune. Alnus is locally present in the middle of the diagram to decrease afterwards, while at the same time wetland herbs show peak values, indicating open wetland vegetation. In contrast with other cores, indicators of open water seem to be absent, which can be explained as a result of the relative high top of the Pleistocene subsoil in the direct vicinity of the river dune.

\section{Botanical macroremains}

Figures 8, 9, 10 and 11 show the macroremains diagrams of cores D, C, B and A. No carbonised plant remains other than charcoal were found in the cores. The absence of carbonised seeds is related to the distance from the location of human activity (especially food preparation) since the excavation revealed considerable numbers of carbonised seeds and fruits there. The cores contain a broad range of taxa, from typical dry land taxa to river bank plants. This variety can be explained by consideration of the deposition processes. At first, presence of local vegetation led to deposition of seeds. Second, seeds from vegetation that grew higher on the river dune moved downwards. Third, river activity may have resulted in deposition of seeds transported by the water, resulting in the presence of drift litter (Cappers 1994). Fourth, flooding may have led to deposition of seeds in places higher than the original habitat. Fifth, people and animals may have played a role in the transport of seeds. The last four processes would result in deposition of seeds that do not necessarily reflect the local vegetation but rather the extra-local or even regional vegetation. The number of dry land taxa is greatest in cores $\mathrm{A}$ and $\mathrm{B}$, related to the distance from the river dune. Macroremains of Quercus, Tilia, Fraxinus, Cornus sanguinea, Corylus avellana and Persicaria maculosa are frequently present. Macroremains of A. glutinosa (seeds, cones, catkins and bud scales) form a major element in all cores, indicating the presence of an alder carr, which is further supported by wood remains in core C and D and seeds of U. dioica, Lythrum salicaria, Carex, Caltha palustris and Berula erecta. The large number of marsh taxa and statoblasts of Bryozoa indicate the presence of shallow water of up to $0.5 \mathrm{~m}$ depth in the local environment. The seeds of $N$. alba indicate a water depth of up to $2 \mathrm{~m}$, but the small number of these seeds as well as of other water plants indicates that these may represent the extra-local vegetation rather than the local vegetation. A special find in core $\mathrm{C}$ is the seed of Leersia oryzoides, a pioneer present in wet and eutrophic conditions.

The macroremains of the cores contain several edible plants, such as Quercus, C. avellana, Prunus spinosa, C. sanguinea and Rubus fruticosus, but remains of crop plants were however not found there. The wild food plant spectrum can additionally be extended by finds from the excavation of non-carbonised seeds and fruits of Malus sylvestris and Crataegus monogyna as well as carbonised seeds/fruits/nuts of $C$. avellana, C. sanguinea, Trapa natans and N. alba. The carbonised state of the latter taxa suggests that people collected and/or consumed the edible parts of these plants. A similar broad range of wild plant food sources is documented at the Hardinxveld sites and the Hazendonk (Bakels 1981; Bakels and Van Beurden 2001; Bakels et al. 2001; unpublished data, Faculty of Archaeology, Leiden University).

The results of the botanical analyses confirm the correlation of the cores based on stratigraphy and ${ }^{14} \mathrm{C}$ dates, although the pollen diagrams from some cores correspond better with each other than the diagrams from others. Zone D-II corresponds with zone B-I since these zones reflect the vegetation before the increase of dry land herbs and shrubs. Zone D-III corresponds with zone B-II and the pollen diagrams of cores $\mathrm{C}$ and $\mathrm{A}$. Limited correspondence of the pollen diagrams from cores $\mathrm{A}$ with cores $\mathrm{C}$ and $\mathrm{D}$ can be explained by the preservation state, the low pollen sums of core $\mathrm{A}$ and differences in the local vegetation.

\section{Discussion}

\section{Natural vegetation}

The river dune vegetation consisted of mixed deciduous woodland with Tilia platyphyllos, Quercus, Ulmus and Fraxinus ( $F$. excelsior) as dominating trees, while Acer (A. campestre) might have been present as well. Betula was probably present in very low numbers in the local and 
Fig. 8 The macroremains diagram of Brandwijk, core D. Concerning seeds and fruits: $+=1-5,++=5-25$,

$+++=25-75$
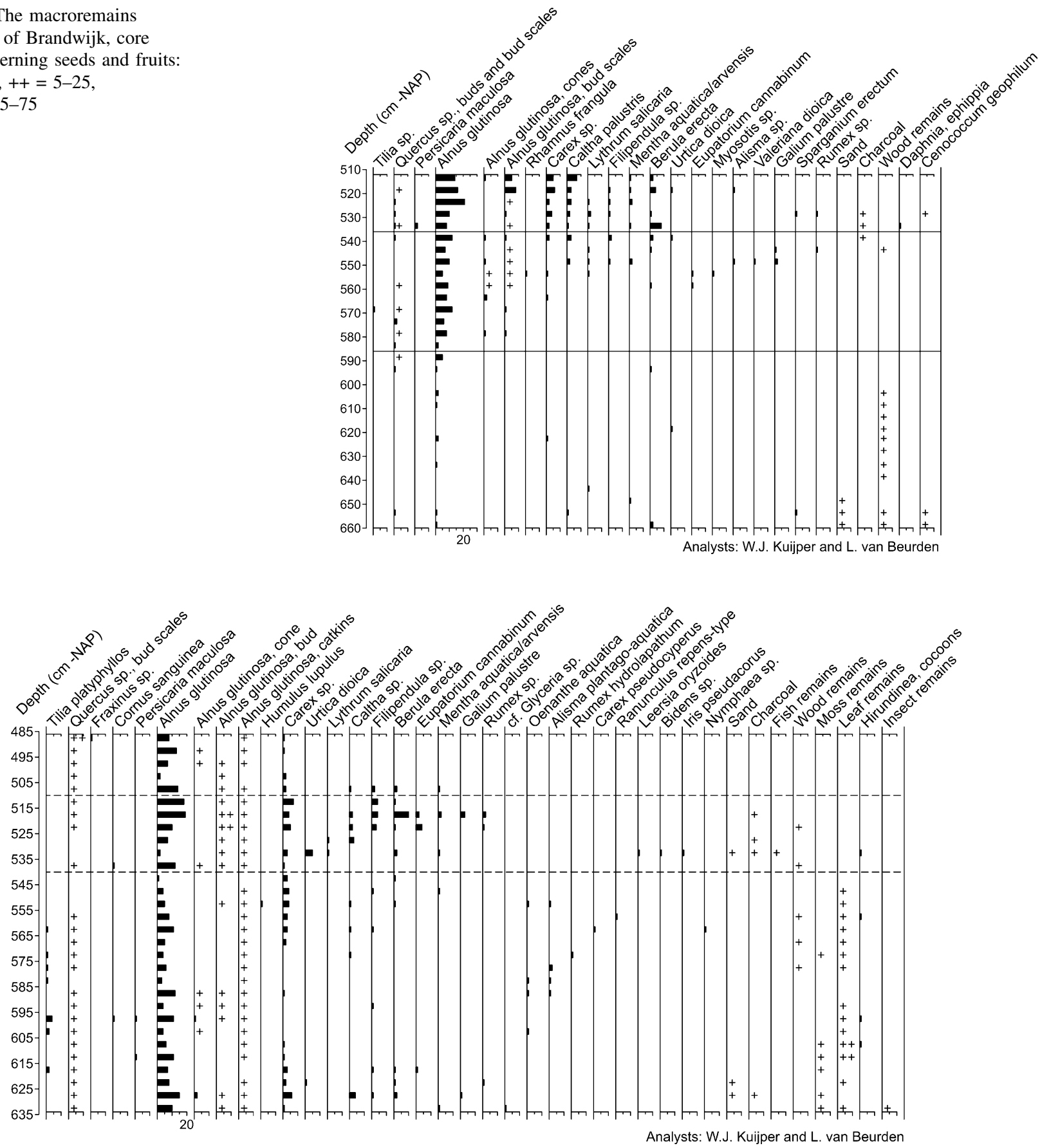

Fig. 9 The macroremains diagram of Brandwijk, core C. Concerning seeds and fruits: $+=1-5,++=5-25,+++=25-75$

extra-local vegetation since it is not present in the assemblages of seeds, wood and charcoal (Hänninen and Vermeeren 1998). Pinus, Picea, Fagus and Carpinus were not present in the local or extra-local vegetation. The main shrubs were $C$. avellana, $R$. cathartica, $V$. opulus and $C$. sanguinea while Ligustrum vulgare, Sambucus and Prunus (probably $S$. nigra and $P$. spinosa) were additionally present as well. This woodland flora is supported by the wood and charcoal identifications from the excavation
(Table 3; Hänninen and Vermeeren 1998). Herbs and ferns like Polypodium, Galeopsis and Moehringia trinervia were common on the slope of the river dune, indicating partly shaded vegetation. Tree falls, activities of wild animals and seasonal changes of the water level probably resulted in the continuous presence of disturbance indicators like Chenopodiaceae and Artemisia. The dry land and wetland vegetation elements would not have been strictly separated as suggested by the distinction of groups in the pollen 
Fig. 10 The macroremains diagram of Brandwijk, core B. Concerning seeds and fruits: $+=1-5,++=5-25$, $+++=25-75$
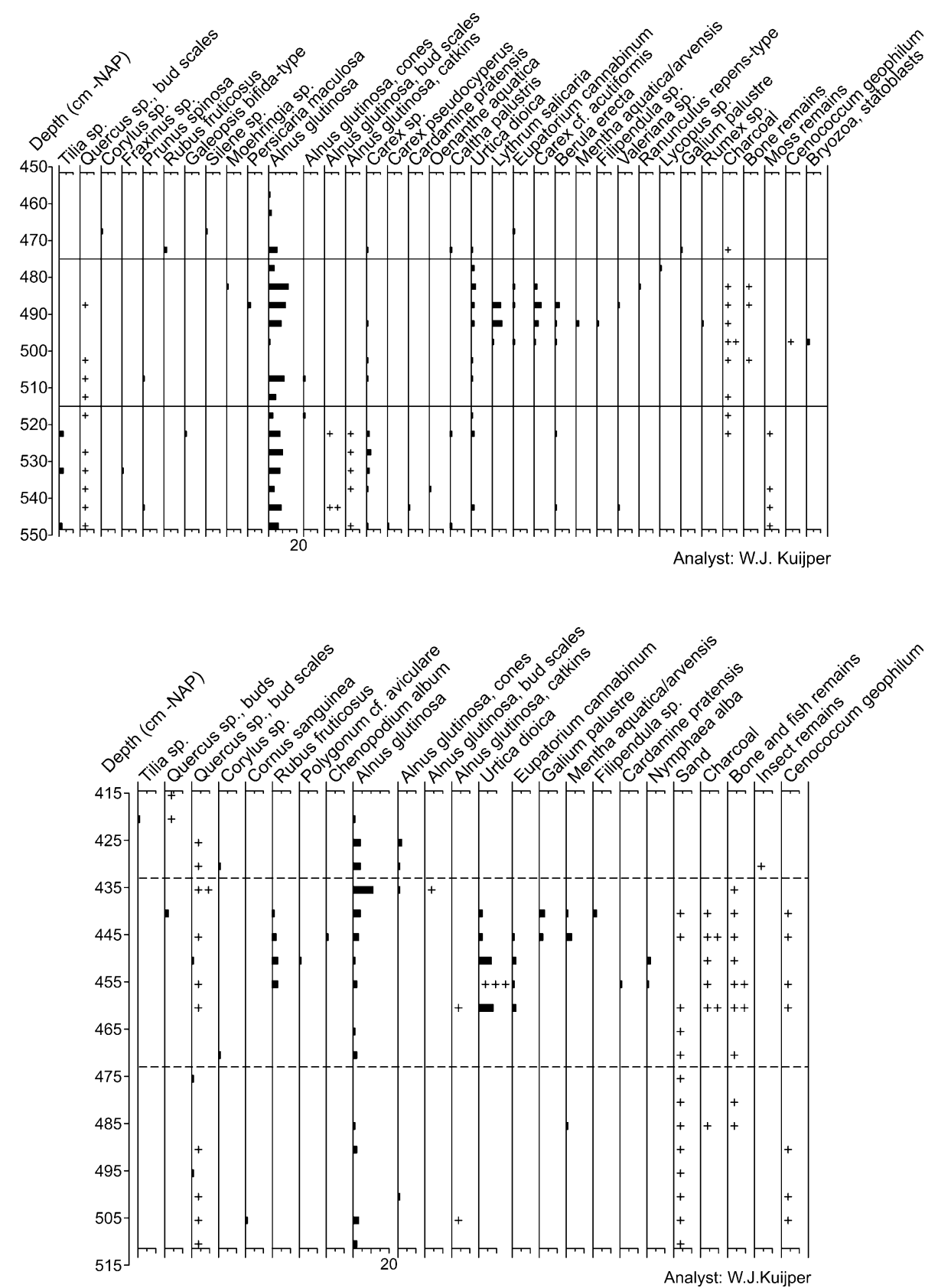

Fig. 11 The macroremains diagram of Brandwijk, core A. Concerning seeds and fruits:

$+=1-5,++=5-25$,

$+++=25-75$ diagrams. Instead a transitional vegetation type of mixed composition probably grew on the slope of the river dune between both vegetation types, dependent on abiotic factors and the ecological requirements of individual plants.

The wetland vegetation was dominated by eutrophic alder carr, consisting primarily of A. glutinosa; additional trees and shrubs were Salix, Rhamnus frangula and Myrica. The main pattern of the wetland vegetation can be characterised as the development from a dense alder carr (lower part, core D) via somewhat more open alder carr and marsh vegetation (middle part, cores $\mathrm{A}, \mathrm{B}, \mathrm{D}$ and the upper part of core C) to a combination of open alder carr, Phragmites vegetation, open marsh and open water (middle and upper parts of all cores). The macroremains diagrams of the cores clearly demonstrate that alder was always present in the near surroundings despite some fluctuations. Both the pollen and seeds comprise many wetland taxa that could have been part of the alder vegetation as well as of the marsh vegetation (for example, Apiaceae, Cyperaceae, ferns, Iris pseudacorus, L. salicaria, Solanum dulcamara and $U$. dioica). A clear distinction between these vegetation types is therefore not possible (Stortelder et al. 1998). The marsh vegetation and riparian plants indicate a water depth between 0 and $50 \mathrm{~cm}$. Floating water plants and riparian plants can form floating vegetation mats in open water, thus resulting in peat formation. This concerns 
Table 3 Wood and charcoal identifications (Hänninen and Vermeeren 1998)

\begin{tabular}{ll}
\hline Wood & Charcoal \\
\hline Alnus sp. & Alnus sp. \\
Cornus sp. & Cornus sp. \\
Corylus sp. & Corylus sp. \\
Fraxinus sp. & Fraxinus sp. \\
Quercus sp. & Quercus sp. \\
Viburnum sp. & Viburnum sp. \\
Euonymus europaeus & \\
Pomoideae & \\
\hline
\end{tabular}

Phragmites australis, Typha angustifolia, Rumex hydrolapathum and N. lutea among others (Weeda et al. 19851994).

Although the sediment of the investigated cores consisted of peat alone, the presence of pollen, seeds and spores of N. alba, N. lutea, Potamogeton, S. natans and $M$. verticillatum demonstrate the presence of stagnant or slowly running, open water with a depth of 0.5-2 m. These indicators of open water are regularly present in limited numbers but reach their maximum values and diversity during the formation of layers 50 and/or 60, and correspond with deposition of clay on the northwestern side of the river dune then. Open water increased accessibility of the river dunes and might have influenced the selection of areas for human activity on the river dune.

\section{Human impact on the vegetation}

Signs of human activity can only carefully be linked with known occupation periods since the chronology of the cores is not known in detail and since there was no section available that linked the stratigraphy of the cores with the excavation. The lowest spectra of core D (-6.60 to $6.46 \mathrm{~m})$ and $\mathrm{C}(-6.35$ to $-6.15 \mathrm{~m})$ may reflect human activity that is probably related to layer 30 . In the relevant spectra of the pollen diagram of core $\mathrm{D}$, the signs of human impact are very weak, characterised by the relative high diversity of dry land shrubs and presence of taxa that indicate open patches ( $U$. dioica-type, Apiaceae, Menthatype). In the macroremains diagram from core $\mathrm{D}$, the evidence of the pollen diagram is supported by the presence of sand. In the macroremains diagram and lithostratigraphy of core $\mathrm{C}$, human impact is reflected by the presence of sand, charcoal and the presence of $U$. dioica. It is the combination of lithostratigraphy, pollen and macroremains of two cores that allows distinction of more open vegetation due to very small-scale human impact. Absence of this possible anthropogenic horizon in cores A and B can be explained by their shallower depth (Fig. 3).
The lower part of zone D-II corresponds with layer 45 and the base of find layer 50. The open landscape in this zone as discussed above may be the result of more or less continuous low-level human influence, resulting in an increase of dry land shrubs and open wetland vegetation. The increasing water level nevertheless played a role as well, as indicated by the presence of indicators of open water and the changes in the wetland vegetation. Zone B-I corresponds with D-II but does not show changes that can be linked to human activity with certainty, despite being closer to the river dune.

The changes in zone D-III correspond with the formation of layers 50 and/or 60. This occupation period has resulted in the strongest anthropogenic signal compared with earlier phases. The pollen diagram of core D shows an increased influx of the regional Pinus pollen, indicating a more open landscape, a slight decrease of Tilia, presence of the anthropogenic indicators Cerealia, Artemisia, Plantago lanceolata, Polygonum persicaria-type and Polygonum convolvulus-type (Behre 1981) and high values of Poaceae, Cyperaceae, S. erectum-type and Apiaceae. Furthermore, Alnus shows low values and the pollen curve of Filipendula shows high values, which may indicate clearance of Alnus carr (Weeda et al. 1985).

Zone B-II corresponds with zone D-III, representing the top of layer 50 and/or 60 . The percentage of Tilia and Alnus in zone B-II is relatively low again. The diversity of dry land shrubs is high, especially in the beginning of the zone, although the number of dry land herbs that indicate human impact is low (Chenopodium album, Artemisia and P. lanceolata). In contrast with cores $\mathrm{C}$ and $\mathrm{D}$, pollen of Cerealia is absent, which might be related to the presence of different activity zones on the river dune, colluviation processes and/or differential preservation.

The pollen diagram of core $\mathrm{C}$, corresponding with D-III and B-II, shows human impact in the middle two spectra. Anthropogenic indicators are, for example, Cerealia pollen and spores of Pteridium. The macroremains and lithostratigraphy clearly show the occupation horizon, indicated by presence of sand, charcoal, fish remains, a decrease of Alnus, and presence of Caltha, B. erecta, Filipendula, $U$. dioica, Eupatorium cannabinum and Mentha aquatica/ arvensis. The pollen diagram from core A does not seem to contain strong indicators of human activity despite correspondence with those parts of other cores that show clear human impact; the low pollen sum however restricts the accuracy of the diagram. The macroremains and lithostratigraphy of this core again show human impact: sand, charcoal, bone remains (including fish remains) and relatively high values of $U$. dioica and E. cannabinum.

The development of the vegetation after occupation is represented in zone B-III (pollen and macroremains), and in the macroremains diagrams in the upper part of cores 
A and C. Decrease of human impact in zone B-III is characterised by partial recovery of Tilia, decrease of the percentage and frequency of dry land shrubs other than Corylus, disappearance of $P$. lanceolata, decrease of charcoal and absence of bone remains. The upper parts of the macroremains diagrams from cores $\mathrm{B}, \mathrm{C}$ and $\mathrm{A}$ all show a decreased number of taxa after the period of occupation. Mainly macroremains of dry land trees, Alnus (dominant) and Carex remain present, representing the natural climax vegetation. These developments indicate that the vegetation recovered and became denser than during the period of human impact. Woodland was still present after occupation on the higher parts of the river dune, indicated by the presence of remains of Tilia, Quercus, Fraxinus and Corylus, despite the small surface of the river dune, the high water table and the effects of occupation.

Summarizing, the diagrams show some evidence of human impact, correlated with layer 30, layer 45 and/or the base of layer 50, and with the top of layer 50 and/or 60 . The first two signs are of minor strength, indicated by an increase of the percentage and diversity of dry land shrubs and a slight increase of wetland herbs that indicate increased presence of light and nutrients, in the pollen diagrams and macroremains diagrams (Filipendula ulmaria, $U$. dioica, B. erecta and E. cannabinum). These changes indicate that the vegetation became somewhat more open. Human impact on the dry land vegetation was however limited, as indicated by the absence of strong changes in the curves of dry land tree taxa in the pollen diagrams (corresponding with absence of evidence for local crop cultivation, discussed below). Generally speaking, it is not possible to reconstruct precisely which parts of the diagrams reflect occupation periods and which parts reflect a lack of occupation, despite the small distance of the sample locations from the river dune (especially concerning core D). It is furthermore not possible to exclude influence of non-human disturbing factors such as the gradual rise of the water table and the influence of wild animals such as beaver and wild boar. The limited strength of human impact at Brandwijk corresponds with the pollen diagrams of the Hardinxveld-Giessendam sites, where it is even more subtle.

Only at ca. $4000-3800$ cal в.C. (5100 в.P.) is strong evidence of human impact visible in the pollen diagrams, corresponding with the formation of layer 50 and/or 60 . While the relationship with changes in the vegetation and human activities remains unclear for the previous phases/ signs of human impact, it is highly likely that these signs are related to human activities, since they are characterised by the presence of charcoal, pollen of crop plants and classical anthropogenic indicators (Behre 1981), followed by partial recovery of the vegetation afterwards. Trees that show recovery after human impact are Tilia and Alnus, which indicates that these were used in some way by people. The analysis of wood and charcoal remains indeed supports the view that Alnus was used (Hänninen and Vermeeren 1998). The use of Tilia is not demonstrated by the wood and charcoal identifications though this might be related to the fact that Tilia wood is rarely preserved.

There are several possible reasons for the strength of the evidence of human impact, described above, that corresponds with formation of layer 50 and/or 60 . In the first place, the intensity of occupation (duration of occupation, number of people, etc.) and the fact that the evidence might represent two occupation periods (the top of layer 50 as well as layer 60) may play a role. Secondly, distance to places of human activities may also play a role. Archaeological investigation by coring demonstrated the presence of only layer 50 on the northwestern side of the river dune, while remains of other layers were concentrated on its southern side (although the analysis of the cores presented here demonstrates the presence of charcoal and bone remains in layers other than 50 north of the river dune as well). This can explain why the lower and middle parts of core $\mathrm{D}$ do not show distinct evidence of human activity. Thirdly, the introduction of crop plants at Brandwijk contemporary with the formation of layer 50 may play a role. It is not possible to differentiate between these hypotheses according to the data currently available.

Influence of increasing distance from the river dune on evidence of human impact

The results only allow analysis of the signs of human impact related to the top of layer 50 and/or 60 to test the hypothesis on the relationship between the evidence of human impact and the distance of the cores from the river dune where this activity took place. Comparison of the anthropogenic evidence in the four cores indicates that there is no linear relationship. It is possible to recognize this evidence of human impact in all cores, and the percentages of dry land shrubs and of dry land herbs characteristic of human impact does not strongly differ between the cores. Only in core A is the signal relatively weak; this is assumed to be related to the poor preservation of the material.

There are several explanations for the limited relationship between distance from the river dune and evidence for human impact. A first explanation is that the relief of the subsoil is more complex than known at the moment. This could explain human impact on vegetation on higher ground if such terrain was present close to cores $\mathrm{C}$ and $\mathrm{D}$, and in similar evidence of human impact in all cores. Geological sources do not, however, confirm this hypothesis. A second explanation is that the distance is too short for a decrease in the evidence for human impact with 
increasing distance from the river dune. Although it is not uncommon for evidence of human impact to be reflected in pollen diagrams over a distance of $20 \mathrm{~m}$ from the site of activity, comparison of pollen diagrams of the nearby Hazendonk shows that such a distance does not exclude the possibility of a decreasing anthropogenic signal. These pollen diagrams from the Hazendonk, reflecting the vegetation on the southwestern side of the river dune near the location of human activities, show that even a distance of $3 \mathrm{~m}$ results in a decrease of the evidence of human impact (Out, unpublished data). A third explanation is that the distance from the cores to the place of human activities is too large since these activities were mainly concentrated on the southern side of the dune during occupation. This hypothesis does not however correspond with finds of archaeological remains on the northern side of the dune. A fourth explanation is that the signs of human impact at Brandwijk-Kerkhof are overruled by the pollen signal from the much larger river dune Brandwijk-Donk, located nearby to the north. It is, however, unlikely that the pollen rain from the larger dune resulted in the presence of herb pollen at Brandwijk-Kerkhof or that the occupation at both dunes took place at exactly the same time, as implied by this argument. A fifth explanation is that the pollen source area of all cores was relatively large compared with the Hazendonk due to open vegetation at Brandwijk, resulting in a highly similar pollen rain at all the sampled locations. This explanation is supported by the presence of open water to the north of the dune during formation of the top of layer 50 and/or 60. Moreover, it is not possible to exclude secondary deposition of pollen due to erosion or people dumping waste, resulting in a similar pollen spectrum over $20 \mathrm{~m}$.

\section{Introduction of crop plants: local crop cultivation?}

The investigated pollen diagrams indicate the presence of cereals from ca. 4000-3800 cal в.c. onwards, contemporary with the top of layer 50 and/or 60, although in contrast, macroremains of crop plants were absent from all cores. Analysis of the macroremains from the excavation, however, demonstrated that layer 50 contained uncarbonised and carbonised grains and some chaff remains of Triticum dicoccum (emmer) and Hordeum vulgare var. nudum (naked barley), and additionally uncarbonised seeds of Papaver somniferum ssp. setigerum (poppy) (Fig. 12). A single grain of Triticum monococcum-type was found in the material of layer 50; this has been interpreted as a grain of $T$. dicoccum that developed in the top of an ear. Layer 60 contained carbonised grains and chaff remains of emmer and naked barley as well. In contrast, analysis of layer 30 (non-representative volume) and ten samples from layer 45 collected from a single section (volume $10 \times 0.151$, mesh width $0.25 \mathrm{~mm}$ ) did not find crop plants in those layers. It is possible that the number of analysed samples and the sampling strategy was too limited to establish the presence of crop plants in layers 30 and 45. However, layer 30 is contemporary with occupation at Hardinxveld-Giessendam where no crop plants have been found either, despite active search and analysis of 50 additional samples (Bakels and Van Beurden 2001; Bakels et al. 2001). The transition to the use of crop plants as shown by the results of this analysis therefore seems to reflect the true transition to the adoption of crop cultivation in the region.

Local crop cultivation at Dutch Neolithic wetland sites has been subject of debate (see Bakels 2000). For Brandwijk it is not clear whether cereals were cultivated locally or whether they were cultivated in the nearby southern sandy regions outside the marsh area and brought in from there. In the pollen cores, cereal pollen was found in cores $\mathrm{C}$ and $\mathrm{D}$. The local conditions at these core sites, however, would have been unsuitable for crop cultivation because of the high ground water level and risk of flooding as indicated by the nearby presence of open water. The cereal pollen was therefore probably dispersed from the river dune itself. There are several arguments that support local crop cultivation on the dune: finds of pollen grains and macroremains of cereals including a small number of chaff remains of free-threshing naked barley, and finds of pollen and macroremains of taxa that may represent arable weeds (not discussed here). There are however also several arguments against local crop cultivation: the excavation did not produce flint artefacts with sickle gloss (Van Gijn, personal communication) and only a single fragment of a quern (a mano; Verbaas, personal communication), the

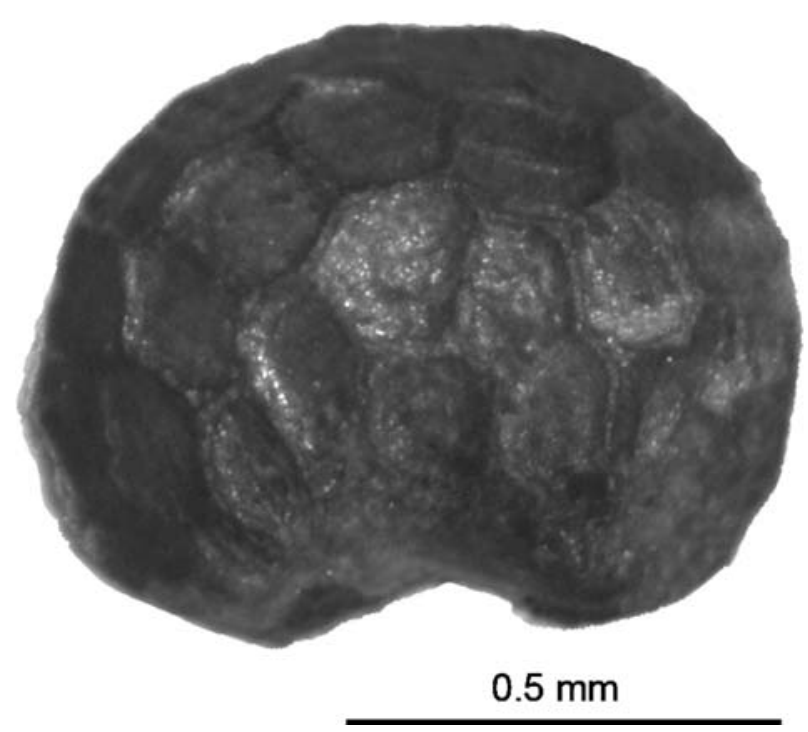

Fig. 12 Papaver somniferum ssp. setigerum (poppy), seed. Size $1.0 \times 0.8 \times 0.7 \mathrm{~mm}$. Photograph: M. van Waijjen, BIAX Consult 
surface of the river dune is rather small for crop cultivation on a subsistence scale, the pollen diagrams do not show large-scale woodland clearance, the presence of cereal pollen can be explained by crop processing rather than cultivation and the presence of pollen grains could be correlated with the presence of waste (see Bakels 1986). Similarly to the Hazendonk, there is not enough evidence to show that cereals were cultivated at Brandwijk, and cereal cultivation at Brandwijk on a considerable scale seems very improbable (Bakels 2000). However, it is possible that there were small plots of arable land on the river dune (horticulture). Considering the few domestic animals in the bone assemblages, it seems that crop cultivation was probably of minor importance for subsistence at Brandwijk. The absence of strong indications of local cereal cultivation furthermore corresponds with the absence of strong signs of human impact on the vegetation as discussed above. The indications for cultivation of poppy at Brandwijk are even less strong than for cultivation of cereals, since the macroremains contained only noncarbonised seeds and concentrations were not found. It is furthermore not clear whether poppy grew as a crop plant or as an arable weed (Bakels 1982). Poppy has been found at only one other pre-Roman Dutch wetland site, Schokland-P14, but the age of this find is unclear (Neolithic; Gehasse 1995).

The introduction of cultivated plants at Brandwijk at the time of deposition of layer 50 is an essential step in the Neolithisation process in the central Netherlands. Based on the results from Brandwijk and the Hardinxveld-Giessendam sites, it must be concluded that crop plants were first introduced between 4220 and 3940 cal B.C. (layer 50), while there are strong indications that they were not present before 4370 cal в.с. (end layer 45). As explained in the introduction, the Brandwijk data fills the gap between that from the Hardinxveld-Giessendam sites and the Hazendonk. The timing of the introduction of crop plants at Brandwijk furthermore strongly corresponds with data from other Dutch wetland sites (Swifterbant S3: 43004000 в.C. and Hazendonk phase 1: 4000 в.с.). Emmer and naked barley have also been found as dominant crops at other Dutch wetland sites that are part of the Swifterbant culture and the related Hazendonk group. The sites concerned are Noordoostpolder-P14 (Gehasse 1995), Swifterbant S3 (Van Zeist and Palfenier-Vegter 1981), Hazendonk phase 1 and 2 (Bakels 1981), and Rijswijk-Ypenburg (Van Haaster 2001), Wateringen 4 (Raemaekers et al. 1997) Schipluiden (Kubiak-Martens 2006) and Hazendonk phase 3 (Bakels 1981), respectively. Considering the influence of the Michelsberg culture on the material culture at the time of the first presence of crop plants at Brandwijk, contacts with this culture might have resulted in the introduction of crop plants as far north as the Rhine/Maas river district.
Earlier introduction of crop cultivation under the influence of the Rössen culture remains an alternative hypothesis (Brinkkemper et al. 1999, p. 82), especially for the more southern sandy dry regions and the IJsselmeer basin from which there is no data so far from the relevant period.

\section{Conclusion}

The natural vegetation of the river dune at Brandwijk consisted of deciduous woodland on its higher parts combined with alder carr and eutrophic freshwater marsh vegetation on the lower slopes and in the surrounding wetland area. The pollen diagrams indicate that human impact was moderate. Only the changes in the pollen diagram contemporary with the top of layer 50 and/or 60 can accurately be attributed to human impact. The pollen and macroremains diagrams show recovery of the vegetation after this period of human impact. Signs of human impact on the river dune are characterised by a slight decrease of Tilia, an increase of shrubs ( $V$. opulus, $R$. cathartica, C. sanguinea, L. vulgare, Sambucus and Prunus), dry land herbs characteristic of human impact (Artemisia, P. lanceolata, P. persicaria-type and Polygonum convolvulus-type), Poaceae and Cyperaceae, wetland herbs that indicate disturbance and open patches $(F$. ulmaria, $U$. dioi$c a, B$. erecta and E. cannabinum), and a decrease in macroremains of Alnus. There is no relationship between increased distance from the dune and strength of the evidence of human impact. The open character of the vegetation may play a role here, although this remains speculative and needs further investigation in the context of comparable sites.

The botanical data from Brandwijk reveals new information on the Neolithisation process in the central Dutch wetlands: there is evidence for introduction of $T$. dicoccum, $H$. vulgare var. nudum and $P$. somniferum ssp. setigerum between 4220 and 3940 cal в.c. There are, however, no strong indications of local crop cultivation at the site itself and the details of the process of introduction of crop cultivation remain unknown. Considering the function of the site, the variety of wild food plants and the indications against local crop cultivation, the importance of crop plants in subsistence seems to have been limited.

Acknowledgments This article is dedicated to Prof. Corrie Bakels on the occasion of her 65th birthday. I would like to thank Corrie for providing the data from Brandwijk. She collected the material herself in the field together with Marten and Wim. I am also grateful to her for stimulating years of education. I would like to thank W.J. Kuijper, L. van Beurden, A. Reinink and D. Paetzold for analysis of the data, and C.C. Bakels, W.J. Kuijper, A.L. van Gijn, A. Verbaas, M. Verbruggen, C.E. Vermeeren, M. van Waijjen, L.P. Louwe Kooijmans, O. Brinkkemper, L.I. Kooistra, referee J. Meurers-Balke and J. Greig for their kind support and useful comments during 
the realisation of this paper. This study was supported by NWO, Netherlands Organization for Scientific Research.

\section{References}

Bakels CC (1981) Neolithic plant remains from the Hazendonk, province of Zuid-Holland, The Netherlands. Zeitschr Archäol 15:141-148

Bakels CC (1982) Der Mohn, die Linearbandkeramik und das westliche Mittelmeergebiet. Archäologisches Korrespondenzblatt 12:11-13

Bakels CC (1986) Akkerbouw in het moeras? (Crop cultivation in the marshes?) Rotterdam Pap 5:1-6

Bakels CC (2000) The Neolithization of the Netherlands: two ways, one result. In: Fairbairn AS (ed) Plants in Neolithic Britain and beyond. Oxbow, Oxford, pp 101-106

Bakels CC, van Beurden LM (2001) Archeobotanie. In: Louwe Kooijmans LP (ed) Hardinxveld-Giessendam Polderweg. Rapportage Archeologische Monumentenzorg 83:325-378

Bakels CC, van Beurden LM, Vernimmen TJJ (2001) Archeobotanie. In: Louwe Kooijmans LP (ed) Hardinxveld-Giessendam De Bruin. Rapportage Archeologische Monumentenzorg 88:369434

Behre K-E (1981) The interpretation of anthropogenic indicators in pollen diagrams. Pollen Spores 23:225-245

Brinkkemper O, Hogestijn W-J, Peeters H, Visser D, Whitton C (1999) The early Neolithic site at Hoge Vaart, Almere, the Netherlands, with particular reference to non-diffusion of crop plants, and the significance of site function and sample location. Veget Hist Archaeobot 8:79-86

Bronk Ramsey C (2005) Oxcal program v3.10. Research Laboratory for Archaeology, University of Oxford, Oxford

Cappers RTJ (1994) An ecological characterization of plant macroremains of Heveskesklooster (The Netherlands). Doctoral thesis, University of Groningen

Fægri K, Iversen J (1989) Textbook of pollen analysis, 4th edn. Fægri K, Kaland PE, Krzywinski K (eds) Wiley, New York

Gehasse EF (1995) Ecologisch-archeologisch onderzoek van het Neolithicum en de Vroege Bronstijd in de Noordoostpolder met de nadruk op vindplaats P14 (Ecological-archaeological investigations of the Neolithic and the Early Bronze Age in the Noordoostpolder, with emphasis on the site P14). Doctoral Thesis, University of Amsterdam

Grimm EC (1991-1993, 2004) TILIA v2.0.b.4 and TGView v2.0 (computer software). Illinois State Museum, Research and Collections Center, Springfield, IL, USA

Hänninen K, Vermeeren C (1998) Hout en houtskool van een donk met bewoningssporen uit het midden Neolithicum in Brandwijk (Z.H.) (Wood and charcoal of a river dune with indications for occupation during the Middle Neolithic at Brandwijk (Z.H.)). Biaxiaal 61

Kubiak-Martens L (2006) Botanical remains and plant food subsistence. In: Louwe Kooijmans LP, Jongste PBF (eds) Schipluiden. A Neolithic settlement on the Dutch North Sea coast, c. 3500 cal BC. Analecta Praehistorica Leidensia 37/38:317-338
Louwe Kooijmans LP (1974) The Rhine/Meuse delta: four studies on its prehistoric occupation and Holocene geology. Analecta Praehistorica Leidensia 7

Louwe Kooijmans LP (1993) Wetland exploitation and upland relations of prehistoric communities in the Netherlands. In: Gardiner J (ed) Flatlands and wetlands: current themes in the East Anglian Archaeology. East Anglian Archaeol Rep 50:71116

Louwe Kooijmans LP (2003) The Hardinxveld sites in the Rhine/ Meuse delta, the Netherlands, 5500-4500 cal BC. In: Larsson L, Kindgren H, Knutsson K, Leoffler D, Åkerlund A (eds) Mesolithic on the move. Papers presented at the sixth international conference on the Mesolithic in Europe, Stockholm 2000. Oxbow, Oxford, pp 608-624

Moore PD, Webb JA, Collinson ME (1991) Pollen analysis. Blackwell, Oxford

Raemaekers DCM (1999) The articulation of a 'New Neolithic'. The meaning of the Swifterbant Culture for the process of Neolithisation in the western part of the North European Plain (4900 3400 BC). Archaeological Studies Leiden University 3

Raemaekers DCM, Bakels CC, Beerenhout B, van Gijn AL, Hänninen K, Molenaar S, Paalman D, Verbruggen M, Vermeeren C (1997) Wateringen 4: a settlement of the Middle Neolithic Hazendonk 3 Group in the Dutch coastal area. Analecta Praehistorica Leiden 29:143-192

Schaminée JHJ et al (1995-1999) De vegetatie van Nederland (The vegetation of the Netherlands), vol 1 (1995); vol 2 (1995); vol 3 (1996); vol 4 (1998); vol 5 (1999). Opulus Press, Uppsala/Leiden

Stortelder AHF, Hommel PWFM, de Waal RW, van Dort RW, Vrielink JG, Wolf RJAM (1998) Broekbossen (Carr vegetation). KNNV-Uitgeverij, Utrecht

Van Gijn AL, Verbruggen M (1992) Brandwijk: Het Kerkhof. In: Woltering PJ, Hessing WAM (eds) Archeologische Kroniek van Holland 1991, 24:348-352

Van Haaster H (2001) Archeobotanisch onderzoek naar de neolithische bewoning op de vindplaats Rijswijk-Ypenburg (Archaeobotanical research concerning Neolithic occupation at the site Rijswijk-Ypenburg). Biaxiaal 188

Van der Meijden R (1996) Heukels' Flora van Nederland. Wolters Noordhoff, Groningen

Van der Woude JD (1983) Holocene paleoenvironmental evolution of a perimarine fluviatile area. Geology and paleobotany of the area surrounding the archaeological excavation at the Hazendonk river dune (western Netherlands). Analecta Praehistorica Leidensia 16

Van Zeist W, Palfenier-Vegter RM (1981) Seeds and fruits from the Swifterbant S3 site. Final reports on Swifterbant 4. Palaeohistoria 23:105-168

Verbraeck A (1974) The genesis and age of the riverdunes (donken) in the Alblasserwaard. Meded Rijks Geol Dienst 25:1-8

Weeda EJ, Westra R, Westra C, Westra T (1985-1994) Nederlandse ecologische flora (Dutch ecological flora), vol 1 (1985); vol 5 (1994). IVN, Amsterdam

Zandstra KJ (1966) The occurrence of Salvinia natans (L.) in Holocene deposits of the Rhine delta. Acta Bot Neerl 15:389 393 